\title{
Critical Review on Smart Chromic Clothing
}

\author{
Esraa El-Khodary ${ }^{1}$, Bahira Gebaly ${ }^{2}$, Eman Rafaat ${ }^{2}$, Ahmed AlSalmawy ${ }^{2}$
}

1. Fashion Design Department, Faculty of Arts \& Design, October University of Modern Sciences and Arts

2. Department of Apparel Design \& Technology, Faculty of Applied Arts, Helwan University

\section{INTRODUCTION:}

Since the beginning of man-kind, designing fashionable clothes has always relied on the textiles used in the process, the only difference between one garment and another is the purpose of it. According to Fred Davis, each piece of clothing has a statement [1] to fulfill while Alison Lurie (1981) has claimed that clothing is a visual language [2] used in communication where Roland Barthes adds that our modern culture has changed nowadays into a visual civilization [3]. With the advancement and progress within the industry, one has seen strategies to support the innovation and creation of new products and functionalities [4]. Such creation and functionalities were reflected on clothing which has enabled to fulfill certain applications. Such materials were then called smart clothing or intelligent clothing. Applications of these clothes may vary. Some of these clothes are used to express creativity and some are used for pure application performance.
Like for example, clothes that has barrier features through which has the ability to protect wearers from hazardous conditions [5]. This is due to global warming is receiving worldwide attention especially since the living conditions are declining [5],[6]. So means to alleviate its harmful consequences has been very much put into consideration [6]. Changes in energy technology have been the necessary target to fulfill which will eventually impact the global economy [7]. Much attention has been paid to the research area of development and perfection of clothes.

Intelligent textiles nowadays are considered to be the next generation of fibres, fabrics and articles [4]. Smart textiles [8] are embedded with sensors and textile structures which allow them to respond to external stimuli and adapt their protective effects accordingly. They are classified as materials that have the capability to think and adapt to the surrounding environment with the aim to fulfill the required need. 


\section{Intelligent clothing are categorized into three groups:}

1) Passive smart clothing: which can only use sensors to sense the environment or the user

2) Active smart clothing: has an embedded actuator function and a sensing device allowing it to sense and react to different stimuli from the surrounding environment

3) Very/Ultra smart clothing: those have the capability of sensing, reaction and adapting their priorities to the environmental conditions [9]

An example of a passive intelligent textile is optical fibers. They are sensitive to deformation and concentration of substances such as pressure, electric power, etc. One the other hand, an example of active intelligent textiles that can react by changing their own colour reliant on the surrounding stimuli $[10,11,12]$ and are called heat-containing textiles. They are well known by chameleonic textile which is the ability to gain or lose energy according to the surrounding temperatures and/or environment [5].

This paper focuses on the different types of chromic materials and how each and everyone one of them is affected by the different external stimuli.

\section{Research Questions:}

This write-up addresses the following questions:

-What is Intelligent Clothing?

-What is the definition of chromic?

- What are the types of chromic Clothing?

- What are the types of applications uses chromic dyes, inks, etc?

-What are the advantages of having chromic clothing?

- Is the Egyptian Community Aware of the Chromic materials?

-What is the preferred chromic material to be applied?

\section{Review:}

When it comes to intelligent textiles and clothing, there is a huge variety. One of these types of intelligent textiles and clothing are those which change their colour reversibly according to external environmental conditions, for this reason they are also called chameleon fibres [13]. Chromic materials are the general term referring to materials which radiate the colour, erase the colour or just change it because its induction caused by the external stimulus, as "chromic" is a suffix that means colour. Therefore we can classify chromic materials depending on the stimulus affecting them [14]. It is known that the coloration process imply electronic transitions between at least two dif- ferent energy levels like for example the chameleon diamond for it to transition from yellow to green it requires at least one electronic transition [15].

There are different chromic materials where each of which reacts in a different way. The cause of change is due to the external stimuli. Application of colour change materials on textile materials are used to produce design effects, functional effects such as camouflage, security printing, brand protection and as mentioned before, use in smart textile applications [16]. The following are different types of chromic materials used in the industry. The two major groups of colour changing inks are the thermochromic and photochromic. They are the most easily applied colour changing inks when used [17]

\section{Photochromic:}

Photochromic, which its external stimulus is light, has the capability to emit reversible colour change when activated by ultraviolet radiation. Photochrromic materials are colourless in a dark environment. However, the ultraviolet radiation changes the molecular structure of the material and it exhibits colour. When the light source is taken away the colour disappears [18]. Photochromic dyes are dispersing dyes. Applying this functional dye to a textile will provides the textile with both a colour changing effect and a UV protective function. Such a textile may find applications in areas such as fancy clothes and camouflage fabrics. Applying these dyes to natural fibers such as wool, cotton and silk, usually results in poor washing fastness [19]. Application of photochromic dyes can be inserted into the fiber matrix using a traditional dyeing technique. The photochromic dye is first blended with a polymer which is then extruded or wet spun into photochromic fibers. Alnother approach os that the dye can be mixed with a resin and surface coated onto fabric surface.

The photochromic colours are commonly used for construction novelty items such as intelligent textiles, toys, cosmetics, clothing and other industrial applications. . in the case of darkness, ultra thin polymers are layered smart textiles, soft products between the laminations allowing for electricity to conduct and therefore electroluminescent light is achieved.

\section{Thermochromic:}

The thermochromic inks have the ability to change its colour regarding the change in temperature. One of the most frequently used materials in printing to achieve the thermochromic effect is the leuco dyes and TC inks [20,21]. The colour of thermochromic prints are very dynamic. It is temperature dependent 
as well as it has the capability to depend on its thermal history. The effect is described by colour hysteresis. Thermochromic materials are protected in round shapes capsules. They are much larger than pigments. The activation temperature is the only parameter given to induce the change of colour [20]. Thermochromic materials can be formulated to change colour when temperatures rise or fall above or below one or more predefined ranges. Thermochromic clothing is accomplished either through embedded dye within the fabric of the apparel, or by the addition of a second fabric embedded with thermochromic dye and affixed to the apparel [22].

As mentioned earlier, thermochromic has been used to serve different applications varying from hazardous applications to artistic applications. There are of course applications specifically in the medical field that lately had been relying on thermochromic clothing. Such an example is baby's clothing. The main aim was from having a baby's clothing made out of thermochromic dyes was to detect when the baby gets too hot or suffers from high fever. Although the clothing extended all over the baby's body yet it was mainly focused in localized areas. Of course that type of clothing achieves the main target of its application since a baby or an infant has no way to communicate or express to their parents. This type of clothing would serve as a visual indicator of the baby's condition and thus a remedial action is taken sooner [22].

Another example of an application is monitoring clothing from cold exposure. This type of invention was the first of its kind to provide early detection and prevent cold exposure to skin surface via thermochromic. It visibly displays dermal temperature by employing thermochromic colour changing characteristics via thermochromic dye incorporated into the fabric of the apparel. The surface appears to be transparent at first until it reaches a certain temperature where at this moment an electron exchange occurs allowing the colour pigment to be released from the capsules. This type of clothing serves in the area of both apparel and health maintenance [23].

There are two chromic systems that have been used successfully in textiles and they are [24]

a. Liquid crystals: they are based on liquid crystals which at certain temperatures the crystals re-orientate which results in an apparent change in colour. The liquid crystals are micro encapsulated, in other words, small particles that are surrounded by a coating. Billions of these capsules, 10 microns in diameter, can be mixed with a suitable carrier to create printing inks for fabric.

b. Molecular Rearrangement: the rearrangement of molecular structure of a dye induces colour change of the thermo chrom material. When the temperature increases the molecules of the system change their arrangement according to the level of the change in temperature. Upon cooling, the system returns back to the first colour due to molecular arrangement [25].

\section{Electrochromic:}

This definition of electrochromism does not, however, fit within the modern sense of the world. An electrochromic material is the one that changes color in a persistent but reversible manner by an electrochemical reaction and the phenomenon is called electrochromism. Electrochromismis the reversible and visible change in transmittance and/or reflectance that is associated with an electrochemically induced oxidation-reduction reaction. It results from the generation of different visible region electronic absorption bands on switching between redox states. The color change is commonly between a transparent ("bleached") state and a colored state, or between two colored states [26]. While its external stimulus is electricity, it is conventional for sun protection system which is associated with darkening the rooms, often requires the use of electric lighting during daytime. The electrochromic switchable coatings, which are applied on glass, have been developed to adapt to both seasonal and environmental changes. This type of coating is also applied to car's mirrors and sun protective glasses [27]. These types of glasses requires to be coated with transparent electrically conductive oxides (TCO) and special electrochromic components which lead to the darkening of the glass fulfilling its application which is sun protection [28]. Although electro chromic glasses are suitable for sun protection applications, yet they suffer from high costs and high weight. Also, any even minor damage usually requires replacement of the entire device [28]. At this point, different materials which are electrochromic may be used as an alternative since they are low in price and can be far better integrated than glass. Such materials are flexible foil [29-31] and textile based materials [32-35].

\section{Piezorochromic:}

Its external stimulus is pressure. Piezoelectric textile fibres are important for wearable energy harvesting applications. Piezoelectric melt-spun fibres have been 
under investigation starting with 2010 . polyvinylidene fluoride (PVDF) which is a widely researched piezoelectric polymer, attempts have been carried out at developing fibres from polypropylene (PP) which has mostly been researched when used in cellular form. Moreover, the piezoelectric behavior of the fibres has until now been characterized, only by the voltage produced by the fibres when they are tested under open circuit conditions. [36].

The primary challenge in electronic textiles is to find materials and devices that provide the desired functionality and that can be easily meshed into hybrid materials. Piezoelectric materials offer significant promise for e-textiles applications. Piezoelectric materials have a number of useful features and are available in a variety of form factors with reasonable cost and development complexity.

Piezoelectric materials are well matched to the needs of e-textiles and wearable computing, offering low power consumption, a choice of form factors, and components with multiple uses. A unique property of piezoelectric is their ability to produce a broad range of voltages, from tens of millivolts to hundreds of volts based on the type and magnitude of the applied stimulus. Piezoelectrics respond to almost any type and magnitude of physical stimulus, including but not limited to pressure, tensile force, and torsion. Piezoelectrics do not have a minimum requirement for producing a response. Their ability to detect the type and magnitude of the stimulus is limited only by the sensitivity of the interface and any contributing environmental variables [37]. One wearable computing application embedded a piezoelectric in the sole of a shoe such that walking motion could be used to generate power [38].

\section{Solvatochromic:}

They are the materials that changes colour when it makes contact with liquid, for example, water [39] and changes back to the original colour when dried. It usually depends on the polarity of the solvents and most of these materials are metal complexes. They are also known as hydro-chromic and aqua-chromic. The process of a hydro-chromic change is for example if a white hydro-chromic ink is sprayed over a background image, what will be seen is a white background but when water falls on the surface, the white sprayed ink disappears allowing the coloured background to show [40]. Such materials are used in swimsuits and umbrellas [39].

\section{Results and Discussion:}

This paper attempted to introduce the variety of chromic materials used in the industry of clothing and how each kind of chromic material is used to serve a certain application. A survey was distributed among 60 people to determine to what extent are the chromic materials known and what type of colour changes is preferred The highest age range that has answered the survey was the age range between 30 to 35 years old representing $37 \%$ while the second highest is the age group of $36+$ representing almost $31 \%$. Most of the people whom answered this survey were adults whom were either housewives or employed.

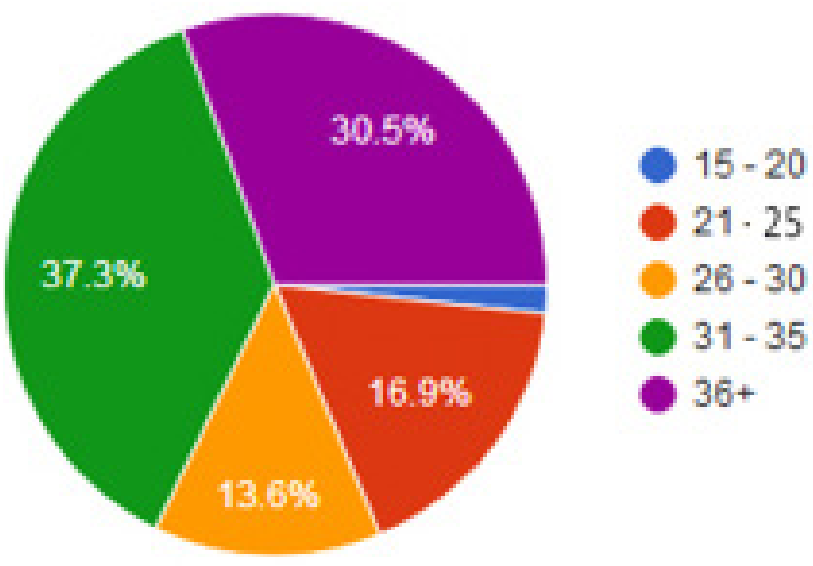

Figure.1 Chart of Age Ranges

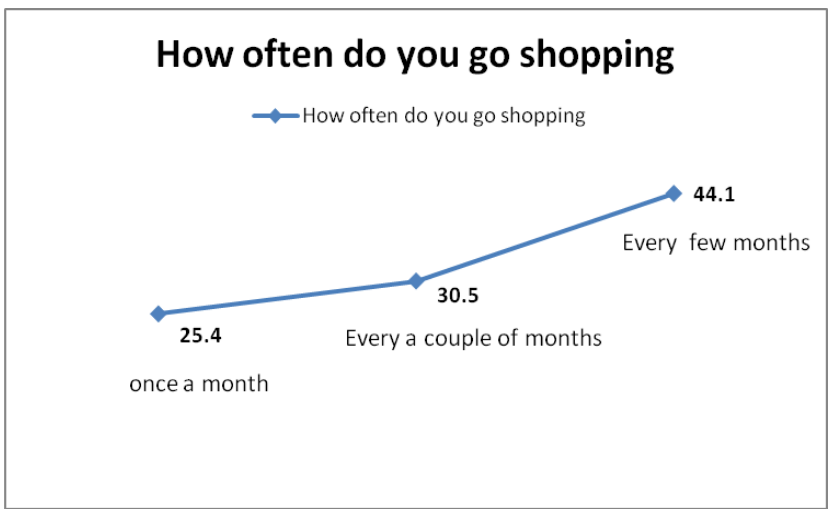

Figure.2 Chart of the Percentage of people how often they go shopping

In the survey, the people were asked to what extent they go shop. Figure 2 shows that $25 \%$ said they go shopping once a month, $31 \%$ said they go shopping every a couple of months while the highest percentage was $44 \%$ and those people shop every few months. Then they were asked if, when shopping, they wish 
they could buy the product in different shades of colour. Figure 3 shows $63 \%$ of people sometimes they wish they could buy the same product in different while $20 \%$ answered an affirmative answer confirming they wish they could the same product in different colours while only $17 \%$ answered with declination.

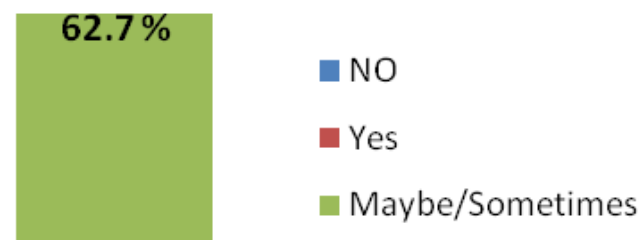

Figure.3 - Percentage of people who would like to buy the same

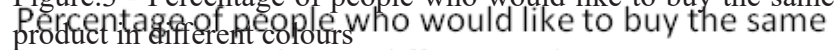
product in different colours

Those people were then asked to what extent they are aware of colour-change clothing. Figure. 4 shows that less than $50 \%$ do know what colour-change clothing is while more than $50 \%$ do not have the knowledge or the awareness of such materials.

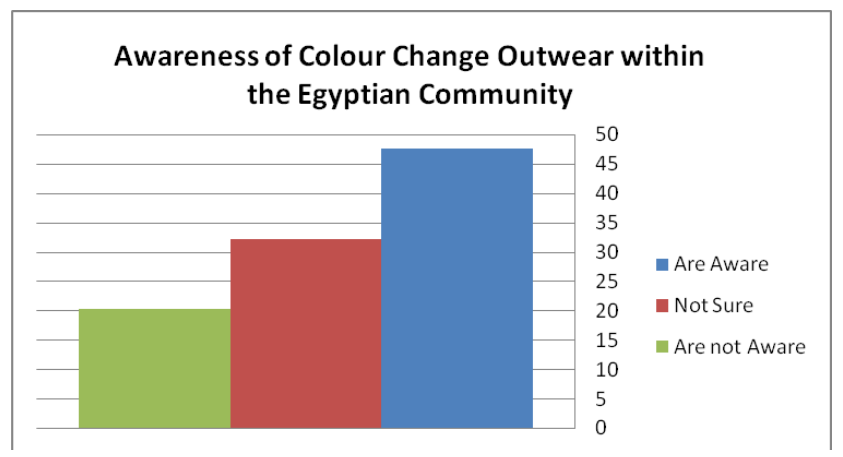

Figure.4 Percent of people's awareness of Colour Change Outwear

So in order to introduce such clothing to the Egyptian market, the survey covered the people's preference when it comes to colour change outwear. As it is reflected in Figure.5, it is shown that the most preferred clothing that contains photochromic prints which in other words changes colour in the sun. The second most preferred was to have a mixture of all chromic materials.

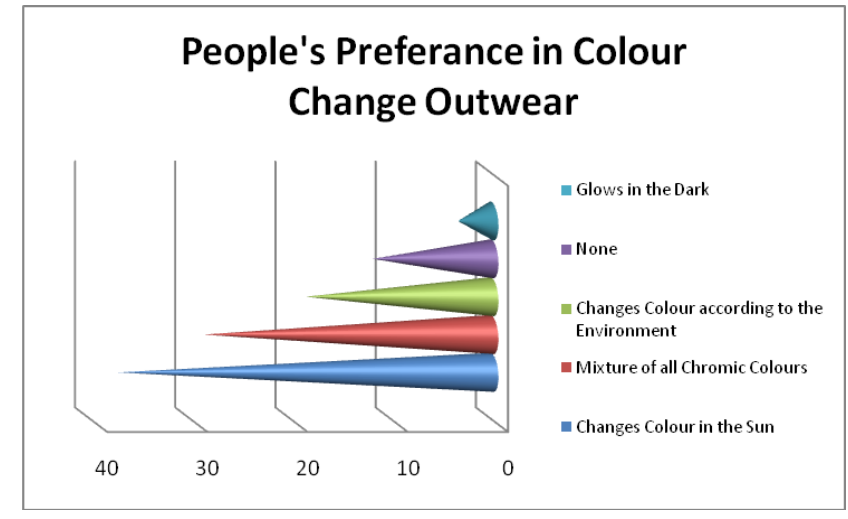

Figure.5 Percent of People's Preference in Colour Change Outwear

\section{Conclusion:}

As a conclusion, the Colour-change chromic colours are not very known in the Egyptian market but yet from the survey people had shown interest in clothing that would have these kinds of prints, or clothes that change their colours in general which is shown in Figure.3. It is encouraged to introduce such materials to manufactures to add it in their lines of production and be introduced to the market to fulfill certain needs and/or applications.

\section{References:}

1. Davis, F. (2013). Fashion, culture, and identity. University of Chicago Press.

2. Lurie, A. (1981). The language of clothes. Random House Inc. 3. Barthes, R. (1983). The fashion system (p. 243). Berkeley: University of California Press.

4.https://tectexntu.wordpress.com/2010/02/11/introduction/

5. Photochromic Textiles and Measurement of Their Temperature Sensitivity Martina Vikova1* and Michal Vik2

6. IPCC, Climate Change 2007: Mitigation, Contribution of Working Group III to the Fourth Assessment Report of the Intergovernmental Panel on Climate Change, in: B. Metz, O.R. Davidson, P. Bosch, R. Dave, L.A. Meyer (Eds.), Cambridge University Press, Cambridge, UK and New York, USA, 2007.

7.N. Stern, The Economics of Climate Change: The Stern Report, Cambridge University Press, Cambridge, UK, 2007.

8. Jocic, D. 2008, 'Smart Textile Materials by Surface Modification with Biopolymeric Systems', Research Journal of Textile and Apparel, vol. 12 no. 2, pp. 58-65.

9.Chika, Y-B. et. al. (2017), Smart Fabrics-Wearable Technology, International Journal of Engineering Technologies and Management Research, Vol. 4 (Iss10)

10.Lopes, F., Neves, J., Campos, A. \& Hrdina, R. 2009, 'Weathering of Microencapsulated Thermo-chromic Pigments', Research, Journal of Textile and Apparel, vol. 13 no. 1, pp. 78-89.

11.Liu, X., Cheng, T., Parhizkar, M., Wang, X.\& Lin, T. 2010, 
'Photochromic Textiles from Hybrid Silica Coating with Improved Photostability', Research Journal of Textile and Apparel, vol. 14 no. 2, pp. 1-8.

12.Sohrabnezhad, S., Pourahmad, A. \& Sadjadi, M. A. 2007, 'New methylene blue incorporated in mordenite zeolite as humidity sensor material', Materials Letters, vol. 61, pp. 2311-2314.

13.Gregory, R. V. et al, (2001), National Textile Center Annual Report (USA), M98 C01.

14.P. Bamfield, Chromic Phenomena: Technological Application of Colour Chemistry, Royal Society of Chemistry Ed., 2002.

15.E.Fritsch et al., (2007), Thermochromic \& photochromic behavior of chameleon diamonds

16.Direct coloration of textiles with photochromic dyes. Part 1: Application of spiroindolinonaphthoxazines as disperse dyes to polyester, nylon and acrylic fabrics_Shah M Reduwan Billah,a Robert M Christiea,* and Renzo Shamey

17.Homola J. 2008, Colour Changing Inks, McGraw Hill yearbook of Science \& Technology

18.Dadi, H.H, 2010, Literature Overview of Smart Textiles, Textilhogskolan.

19.Cheng, T, 2007, Centre of Material and Fibre Innovation, Deakin University, Vol 77(12): 923-928 http://www.trj.sagepub. com

20.Rahela Kulcar, et al. Dynamic Colour Possibilities and Functional Properties of Thermochromic Printing Inks, ACTA Graphica 202, 2012

21.Seeboth A., et al., 2006, Thermochromic Phenomena in Polymers, Shawbury: Smithers Rapra Technology Limited, 17.

22.Suffolk, C.E, 2010, Baby Clothing Comprising a Thermochromic material, patent no.: US2010/0313325

23.Matheson, J.P, 2012, Thermochromic Temperature Monitoring Clothing, Pub no: US2009/0040760AI

24.The Belgium Textile Research Centre, 2010, http://www.centexbel.com

25.http://indiantextilejournal.com/articles/FAdetails.asp?

26.Somani, P.R., 2002, Electrochromic materials and devices: present and future, Materials Chemistry and hysics 77, 117-133

27.Rauh, R.D. et al, 1999, Electrochim, Acta, 44, 3165

28.Schawaller, D. et al., 2014, Flexible, Switchable Electrochromic Textiles, Macromol.Mater.Eng, 299, 330-335

29.Jensen, J., et al., 2012, J. Polym. Sci. B: Polym Physics, 50, 536.

30.Sondergaard, R.R., et al., 2013, J. Polym. Sci. B: Polym Physics, 51,132

31.Sondergaard, R.R., et al., 2013, J. Polym. Sci. B: Polym Physics, 51,16

32.Savitha, K.U., et al., et al., 2013, J. Appl. Polym. Sci., 127, 3247

33.Invernale, M. A., Ding, Y., \& Sotzing, G. A. (2011). The effects of coloured base fabric on electrochromic textile. Coloration Technology, 127(3), 167-172.

34.Molina, J., \& Esteves, M. F. (2001). J. Fern andez, J. Bonastre, F. Cases. Eur. Polym. J, 47, 2003.

35.Kelly, F. M., Meunier, L., Cochrane, C., \& Koncar, V. (2013). Polyaniline: Application as solid state electrochromic in a flexible textile display. Displays, 34(1), 1-7..

36.Matsouka, D., Vassiliadis, S., \& Bayramol, D. V. (2018). Piezoelectric textile fibres for wearable energy harvesting systems. Materials Research Express, 5(6), 065508.

37.Edmison, J., Jones, M., Nakad, Z., \& Martin, T. (2002, October). Using piezoelectric materials for wearable electronic textiles. In Proceedings. Sixth International Symposium on Wearable Computers, (pp. 41-48). IEEE.

38.Kymissis, J., Kendall, C., Paradiso, J., \& Gershenfeld, N. (1998, October). Parasitic power harvesting in shoes. In Digest of Papers. Second International Symposium on Wearable Computers (Cat. No. 98EX215) (pp. 132-139). IEEE.

39.Merati, A. A. (2013). Smart textiles. HISTORY, PROPERTIES AND PERFORMANCE AND APPLICATIONS, 239.

40.Mal, P., \& Iqbal, S. (2014). Chromic Materials in Textiles. BS Publications, 557. 